\title{
Vibration Isolation System Using Negative Stiffness
}

\author{
Taksehi Mizuno \\ Saitama University \\ Japan
}

\section{Introduction}

Vibration isolation plays an important role in the operation of many advanced production and measurement systems such as semiconductor manufacturing and high-precision measuring. Rapid technological developments in these fields have increased the need for higher-performance vibration isolation systems.

There are two kinds of vibration that must be reduced by a vibration isolation system:

1. vibration transmitted from the ground through the suspension (ground vibration),

2. vibration caused by disturbances acting on an isolation table (direct disturbance).

A suspension with less stiffness is better for reducing the former because dynamic coupling between the vibration source and the isolation table is weakened; thus, zero stiffness is ideal. However, higher stiffness is better for suppressing the latter because it reduces displacement of the isolation table from its desired position; thus, infinite stiffness is ideal. In conventional passive-type vibration isolation systems, a trade-off between lower and higher stiffness is inevitable, so that performance is limited.

In contrast, active-type vibration isolation systems do not suffer from such performance limitations (Rivin, 2003). In particular, the performance limitations of passive-type vibration isolation systems can be effectively overcome by two-degrees-of-freedom control (Yasuda et al., 1996). There are also various control methods applied according to required performance and acceptable cost. One of the fundamental control strategies is to provide feedback regarding the absolute velocity of the isolation table, which is often referred to as skyhook damping (Fuller et al., 1996). State feedback (Miyazaki et al., 1994), feedforward (Mohamed et al., 2005) and active acceleration control (Zhu et al., 2006) have also been applied. Meanwhile, most active vibration isolation systems use high-performance sensors, such as servo-type accelerometers, to detect the vibration of an isolation table with high sensitivity in a low-frequency domain. Since these sensors are costly, active systems are more expensive than passive systems, sometimes by a factor of ten, which represents a critical obstacle to expanding their fields of application.

This chapter presents a novel solution to the problem of vibration isolation (Mizuno et al., 2006a). It uses suspension with negative stiffness. Infinite stiffness against direct disturbances acting on the isolation table can be achieved by combining the suspension with a normal spring. As a result, direct vibration is suppressed while system vibration transmitted from the ground is reduced. Suspension with negative stiffness can be achieved by using only relative-displacement sensors, which cost far less than servo-type 
accelerometers. This chapter describes the principles of vibration isolation system using negative stiffness and the control methods of realizing negative stiffness.

The application of negative stiffness to vibration isolation was previously reported by Platus (1999) and Trimboli et al. (1994). In their work, a negative spring was used in parallel with a positive spring to lower the stiffness of suspension. In our approach, by contrast, serial connection of a negative spring and a positive spring is applied to vibration isolation system.

\section{Principles of vibration isolation system using negative stiffness}

\subsection{Basic configuration}

The concept of the proposed vibration isolation is illustrated by using Fig.2.1. When two springs with spring constants $k_{1}$ and $k_{2}$ are connected in series, the total stiffness $k_{c}$ is given by (Mizuno et al., 2006a)

$$
k_{c}=\frac{k_{1} k_{2}}{k_{1}+k_{2}} .
$$

This equation shows that when normal springs are connected the total stiffness becomes lower than the stiffness of each spring. However, if one of the springs has negative stiffness

$$
k_{1}=-k_{2},
$$

the resultant stiffness becomes infinite:

$$
\left|k_{c}\right|=\infty \text {. }
$$

This principle of generating high stiffness is applied to vibration isolation system to counteract direct disturbances acting on the isolation table.

Figure 2.2 shows a conceptual model of the proposed vibration isolation system (Mizuno et al., 2003a). A middle mass $m_{1}$ is supported by a spring $k_{1}$ with positive stiffness (positive spring) and a damper $c_{1}$; they work like a passive suspension. A linear actuator fixed on the middle mass supports a isolation table $m_{2}$. The actuator is controlled to have negative stiffness $-k_{n}$ as shown in Fig.2.3. In the initial steady states (Fig.2.3a), the distance between the table $m$ and the base is kept to be $L$. When downward force $\Delta F$ is applied to the table, the distance increases by $\Delta L$ as shown in Fig.2.3b. The displacement of the table is in the direction opposite to the added force so that the static stiffness of the suspension is given by

$$
-\frac{\Delta F}{\Delta L}\left(\equiv-k_{n}\right)
$$

This system can reduce vibration transmitted from ground by making $k_{1}$ small because the dynamic coupling between the vibration source (ground) and the isolation table via the middle mass is weakened. At the same time, infinite stiffness can be produced to counteract direct disturbances by setting the amplitude of negative stiffness $k_{n}$ equal to $k_{1}$. To explain such action more concretely, it is assumed that the table is subject to a downward force. The distance between the middle mass and the table becomes larger because of the negative stiffness; that is, the table would move upwards if the middle mass were fixed. Meanwhile, 


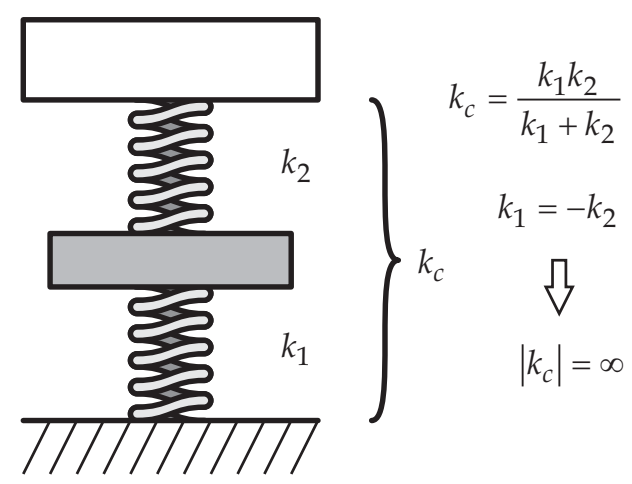

Fig. 2.1. Series connection of two springs

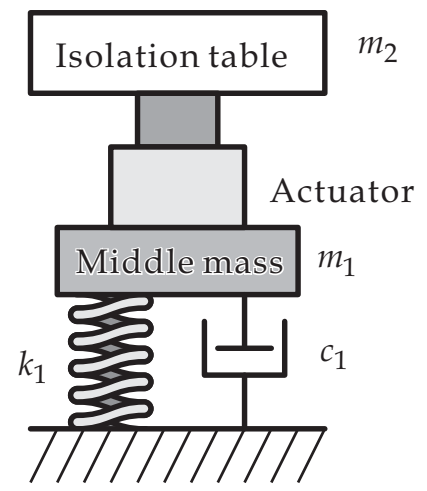

Fig. 2.2. Basic structure of vibration isolation system

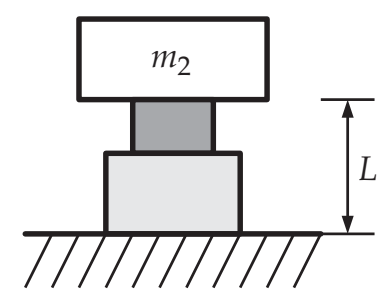

(a) Initial state

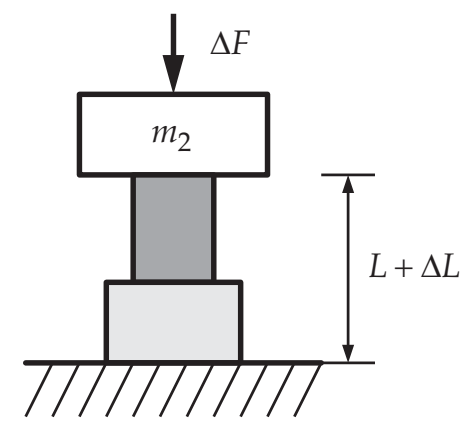

(b) Downward force is applied

Fig. 2.3. Negative stiffness achieved by the actuator

the middle mass moves downwards because of positive stiffness. The increase in the distance is cancelled by the downward displacement of the middle mass due to the above-mentioned setting. Thus, the isolation table is maintained at the same position as before. 
It is to be mentioned that suspension with negative stiffness can be achieved by using only relative-displacement sensors, which cost far less than servo-type accelerometers.

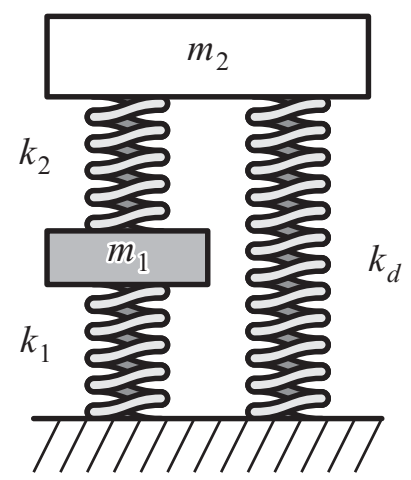

Fig. 2.4. Introduction of a parallel spring

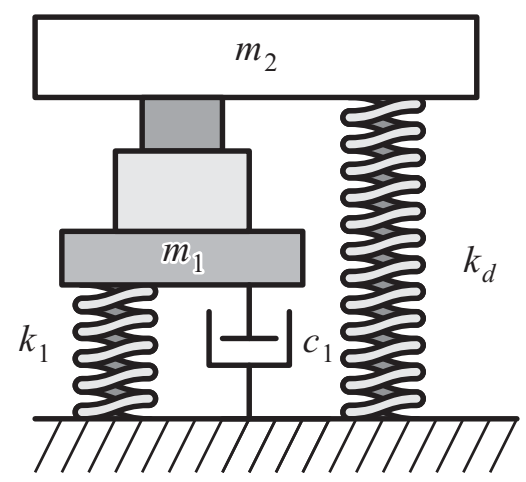

Fig. 2.5. Vibration isolation system with a weight support mechanism

\subsection{Introduction of weight support mechanism}

In the system shown by Fig.2.2, the entire weight of the isolation table is supported by the linear actuator. When the isolation table is large, therefore, high-power actuators are needed to suspend its weight, which will raise the cost of system. Such problem can be overcome by introducing an auxiliary suspension for supporting the weight of the isolation table, as explained in Fig.2.4 (Mizuno et al., 2006a). A spring $k_{d}$ is added in parallel with the serial connection of the positive and negative springs. The total stiffness $\tilde{k}_{c}$ is given by

$$
\tilde{k}_{c}=\frac{k_{1} k_{2}}{k_{1}+k_{2}}+k_{d}
$$

When Eq. (2.2) is satisfied, the resultant stiffness becomes infinite for any finite value of $k_{d}$.

$$
\left|\tilde{k}_{c}\right|=\infty \text {. }
$$


Figure 2.5 shows the configuration of one of the proposed vibration isolation systems. A spring $k_{d}$ is inserted between the isolation table and the base. The spring is set to reduce the suspension force produced by the actuator in the equilibrium state. It should be noted that isolation from ground vibration can be maintained by using a soft spring as $k_{d}$.

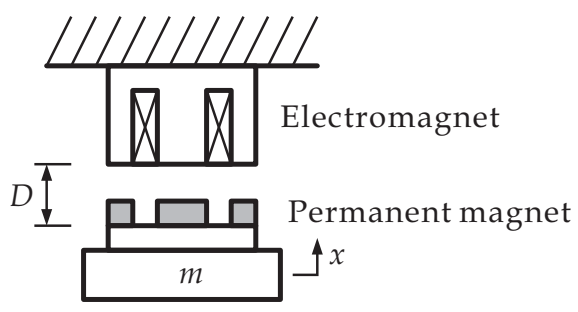

Fig. 3.1. Basic model of zero-power magnetic suspension system

\section{Realization of negative stiffness}

\subsection{Zero-power control}

Controller design. To maintain stability, suspension with negative stiffness is realized by using active control. The original system has used zero-power magnetic suspension. Due to its power-saving properties, zero-power control has been used in magnetic suspension systems such as momentum wheels for spacecraft stabilization (Sabnis et al., 1975) and carrier systems in clean rooms (Morishita et al., 1989). In this form of control, a hybrid magnet consisting of an electromagnet and a permanent magnet is used. Control of the electromagnet makes steady deviation of the coil current converge to zero. As a result, the air-gap length is maintained so that the attractive force generated by the permanent magnet balances the other, static forces acting on the suspended object.

Figure 3.1 shows a single-degree-of-freedom-of-motion model for analysis (Mizuno \& Takemori, 2002). A hybrid magnet consisting of a permanent magnet and a pair of electromagnets is used for generating suspension force. The suspended object with a mass of $m$ is assumed to move only in the vertical direction translationally. The equation of motion is given by

$$
m \ddot{x}(t)=k_{s} x(t)+k_{i} i(t)+f_{d}(t),
$$

where $x$ is the displacement of the suspended object, $k_{s}$ and $k_{i}$ are, respectively, the gapforce and current-force coefficients, $i$ is the control current, and $f_{d}$ is the disturbance force acting on the suspended object. The transfer function representation of the dynamics described by Eq. (3.1) becomes

$$
X(s)=\frac{1}{t_{o}(s)}\left(b_{0} I(s)+d_{0} F_{d}(s)\right),
$$

in which each Laplace-transformed variable is denoted by its capital, and

$$
\begin{gathered}
t_{0}(s)=s^{2}-a_{0}, \\
a_{0}=\frac{k_{s}}{m}, \quad b_{0}=\frac{k_{i}}{m}, \quad d_{0}=\frac{1}{m} .
\end{gathered}
$$


The zero-power control operates to accomplish

$$
\lim _{t \rightarrow \infty} i(t)=0 \text { for stepwise disturbances, }
$$

In discussing the zero-power control, therefore, disturbance should be considered to be stepwise.

$$
F_{d}(s)=\frac{F_{0}}{s} \quad\left(F_{0}: \text { const }\right),
$$

Considering linear output feedback control, the control input can be represented as

$$
I(s)=-\frac{h(s)}{g(s)} X(s),
$$

where $g(s)$ and $h(s)$ are coprime polynomials in $s$. They are selected for the closed-loop system to be stable.

Substituting Eq. (3.7) into Eq. (3.2) gives

$$
X(s)=\frac{g(s)}{t(s)} d_{0} F_{d}(s),
$$

where

$$
t(s)=\left(s^{2}-a_{21}\right) g(s)+a_{23} h(s) .
$$

Substituting Eqs. (3.6) and (3.8) into Eq. (3.7) gives

$$
I(s)=-\frac{h(s)}{t(s)} d_{0} \cdot \frac{F_{0}}{s} .
$$

To achieve the control object described by Eq. (3.5), $h(s)$ must satisfy

$$
h(s)=\operatorname{sh}(s),
$$

where $\tilde{h}(s)$ is an appropriate polynomial. Therefore, the control input achieving zero-power control is represented by

$$
I(s)=-\frac{s \tilde{h}(s)}{g(s)} X(s) .
$$

Figure 3.2(a) shows a general form of zero-power controller (Mizuno \& Takemori, 2002). Since velocity is the time derivative of displacement, it indicates that an approach for achieving the zero-power control is

[Approach 1] Feeding back the velocity of the suspended object.

Substituting Eq.(3.12) into Eq.(3.7) and transforming it gives

$$
I(s)=-\frac{s \tilde{h}(s)}{g(s)} X(s)=-\frac{1}{1-\frac{\tau}{s}} \cdot \frac{(s-\tau) \tilde{h}(s)}{g(s)} X(s) .
$$


Controller
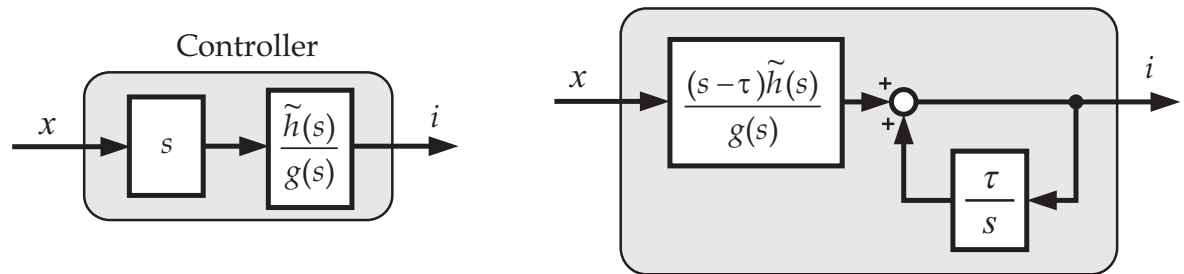

(a) Velocity feedback

(b) Corrent integral feedback

Fig. 3.2. General forms of zero-power controller

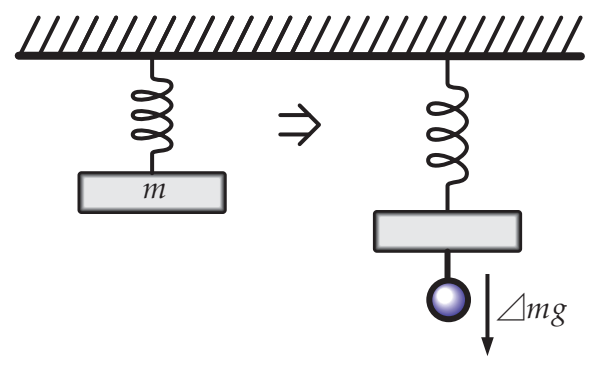

(a) Normal spring

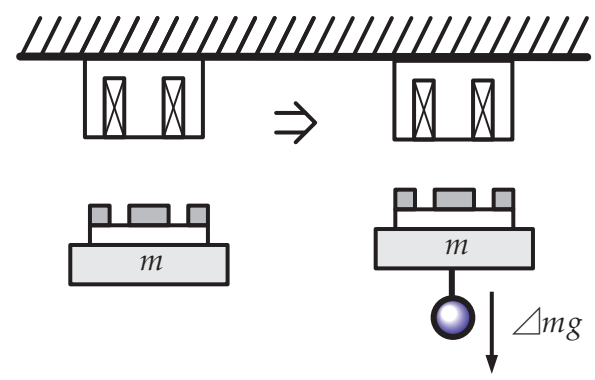

(b) Zero-power magnetic suspension

Fig. 3.3. Comparison of zero-power magnetic suspension with a normal spring

where $\tau$ is a parameter introduced for the transformation. Figure 3.2(b) shows the transformed block diagram. It indicates another approach for achieving virtually zeropower control:

[Approach 2] Introducing a minor feedback of the integral of current.

In actual implementation, this configuration is more often used which is combined with PD control as mentioned in Section 4.1.

Negative Stiffness. A unique characteristic of the zero-power control system is that it behaves as if it has negative stiffness. When an external force is applied to the mass in a common mass-spring system, the mass moves to the direction of the applied force, as shown in Fig.3.3a. In the system controlled by zero-power, the suspended object moves to a new equilibrium position located in the direction opposite to the applied force, as shown in Fig.3.3b. This characteristic is shown analytically in the following.

At steady state, the suspended object is maintained at a position such that

$$
0=k_{s} x(\infty)+k_{i} i(\infty)+F_{0} .
$$

In the zero-power control system, the coil current is controlled to converge to zero, that is

$$
i(\infty)=0 .
$$

Therefore, 


$$
x(\infty)=-\frac{F_{0}}{k_{s}} .
$$

The negative sign on the right-hand side indicates that the new equilibrium position is in a direction opposite to the applied force.

\subsection{Stiffness control (linear actuators)}

In the zero-power magnetic suspension system, however, the magnitude of negative stiffness is a function of the gap between the electromagnet and the suspended object. When the mass on the isolation table changes, therefore, the negative stiffness varies from the nominal value so that the stiffness against disturbances acting on the isolation table becomes lower (Mizuno et al., 2006a).

Suspension with negative stiffness can be also realized with other linear actuators such as voice coil motor and pneumatic cylinder. The actuator is controlled to behave as shown by Fig.2.3. In this section, the design of control system for realizing negative stiffness is described. A voice coil motor (VCM) is adopted as an actuator (Mizuno et al., 2003a).

Figure 3.4 shows a single-degree-of-freedom model used in analysis. The equation of motion is

$$
m \ddot{x}+c_{a} \dot{x}+k_{a} x=f_{a}+f_{d},
$$

where $m$ : mass of the table, $x$ : displacement from the equilibrium point, $k_{a}$ : stiffness of supporting spring, $c_{a}$ : damping coefficient of support, $f_{a}$ : force generated by the actuator, $f_{d}$ : direct disturbance acting on the table. Since the force generated by the actuator is proportional to the coil current $i, f_{a}$ is given by

$$
f_{a}=k_{i} i,
$$

where $k_{i}$ : current-force coefficient. From Eqs.(3.17) and (3.18), we get a transfer representation of the dynamics:

$$
X(s)=\frac{1}{s^{2}+a_{1} s+a_{0}}\left(b_{0} I(s)+d_{0} F_{d}(s)\right)
$$

where

$$
a_{0}=\frac{k_{a}}{m}, \quad a_{1}=\frac{c_{a}}{m}, \quad b_{0}=\frac{k_{i}}{m}, \quad d_{0}=\frac{1}{m} . .
$$

The displacement of the table is treated as an output signal here. When linear control law is applied, therefore, the control input is generally represented as

$$
I(s)=-\frac{h(s)}{g(s)} X(s) .
$$

When the transfer function of the controller is proper, the polynomials are represented as

$$
g(s)=s^{n}+\sum_{k=0}^{n-1} g_{k} s^{k},
$$




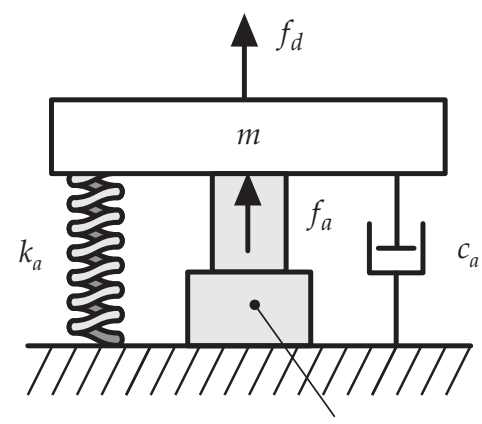

Voice coil motor

Fig. 3.4. Basic model with voice coil motor

$$
h(s)=\sum_{k=0}^{n} h_{k} s^{k} .
$$

Substituting Eq.(3.21) into Eq.(3.19) leads to

$$
X(s)=\frac{g(s)}{\left(s^{2}+a_{1} s+a_{0}\right) g(s)+b_{0} h(s)} d_{0} F_{d}(s) .
$$

The disturbance is assumed to be stepwise so that it is represented as Eq.(3.6). It is assumed that the controller is selected to stabilize the closed loop system. The steady-state displacement $x(\infty)$ is given by

$$
\frac{x(\infty)}{F_{0}}=\lim _{s \rightarrow 0} \frac{g(s)}{\left(s^{2}+a_{1} s+a_{0}\right) g(s)+b_{0} h(s)} d_{0}=\frac{d_{0} g_{0}}{a_{0} g_{0}+b_{0} h_{0}} .
$$

For the system to have negative stiffness with a magnitude of $k_{n}$, the following equation must be satisfied

$$
\frac{d_{0} g_{0}}{a_{0} g_{0}+b_{0} h_{0}}=-\frac{1}{k_{n}}
$$

For assigning the closed-loop poles arbitrarily, second- or higher-order compensators are necessary. When a second-order compensator is used, the characteristic polynomial of the closed-loop system becomes

$$
\begin{aligned}
t_{c}(s) & =s^{4}+\left(a_{1}+g_{1}\right) s^{3}+\left(a_{0}+g_{0}+a_{1} g_{1}+b_{0} h_{2}\right) s^{2} \\
& +\left(a_{0} g_{1}+a_{1} g_{0}+b_{0} h_{1}\right) s+\left(a_{0} g_{0}+b_{0} h_{0}\right) .
\end{aligned}
$$

To obtain a system with a characteristic equation of the form

$$
t_{d}(s)=s^{4}+e_{3} s^{3}+e_{2} s^{2}+e_{1} s+e_{0},
$$

we can match coefficients to obtain 


$$
\begin{gathered}
g_{0}=-\frac{e_{0}}{d_{0} k_{n}}=-e_{0} \frac{m}{k_{n}}, \\
g_{1}=e_{3}-a_{1}, \\
h_{0}=\frac{1}{b_{0}}\left(e_{0}-a_{0} g_{0}\right), \\
h_{1}=\frac{1}{b_{0}}\left(e_{1}-a_{0} g_{1}-a_{1} g_{0}\right), \\
h_{2}=\frac{1}{b_{0}}\left(e_{2}-a_{0}-g_{0}-a_{1} g_{1}\right) .
\end{gathered}
$$

It is to be montioned that the zero-power controller can be designed in a similar way (Mizuno \& Takemori 2002).

\section{Vibration isolation systems using zero-power magnetic suspension}

There are a variety of configurations of system for vibration isolation using negative stiffness. This section treats vibration isolation systems using zero-power magnetic suspension for achieving negative stiffness.

\subsection{Single-axis system}

Basic Structure. Figure 4.1 shows a basic configuration of vibration isolation system using zero-power magnetic suspension. A middle mass is connected to the base through a spring $k_{1}$ and a damper $c_{1}$, which together work as a conventional vibration isolator. An electromagnet for zero-power magnetic suspension is fixed to the middle mass. The part of an isolation table facing the electromagnet is made of a soft iron material for confining the magnetic fields produced by the permanent magnets for zero-power control. This is referred to as the reaction part (Mizuno et al., 2006a).

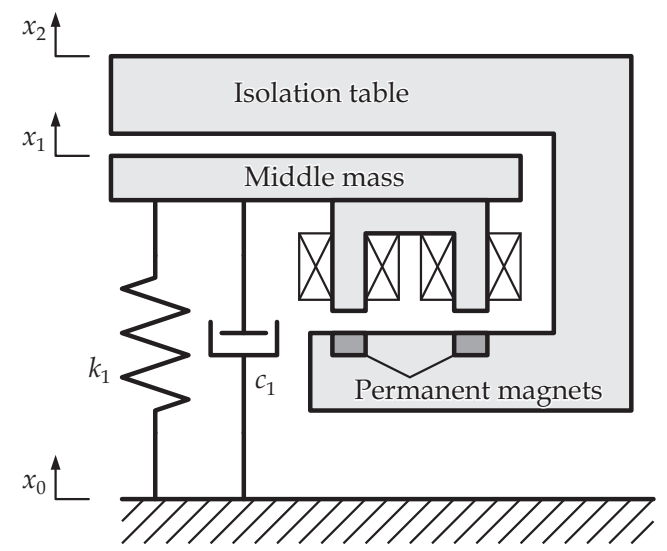

Fig. 4.1. Basic structure of vibration isolation system using zero-power magnetic suspension 


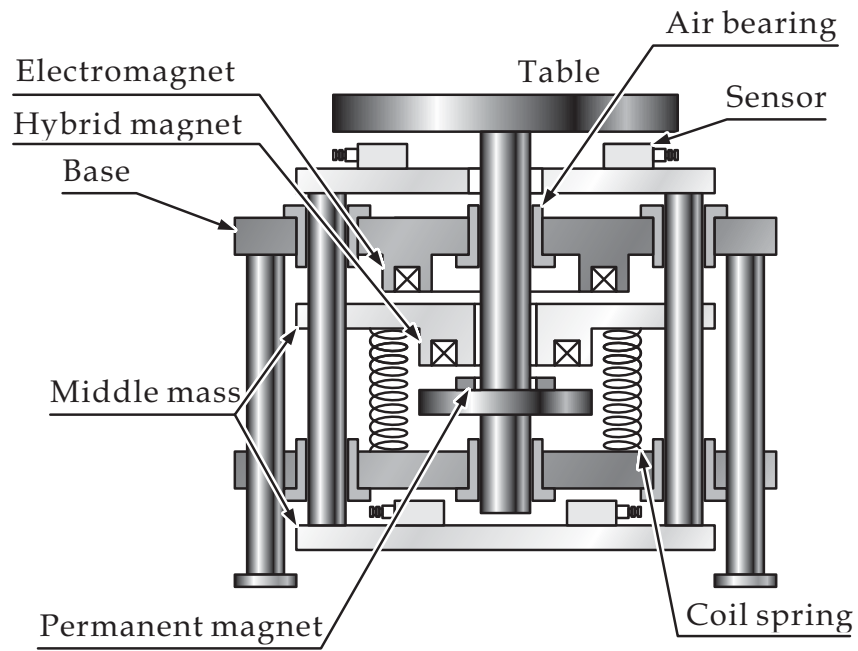

Fig. 4.2. Schematic drawing of experimental apparatus

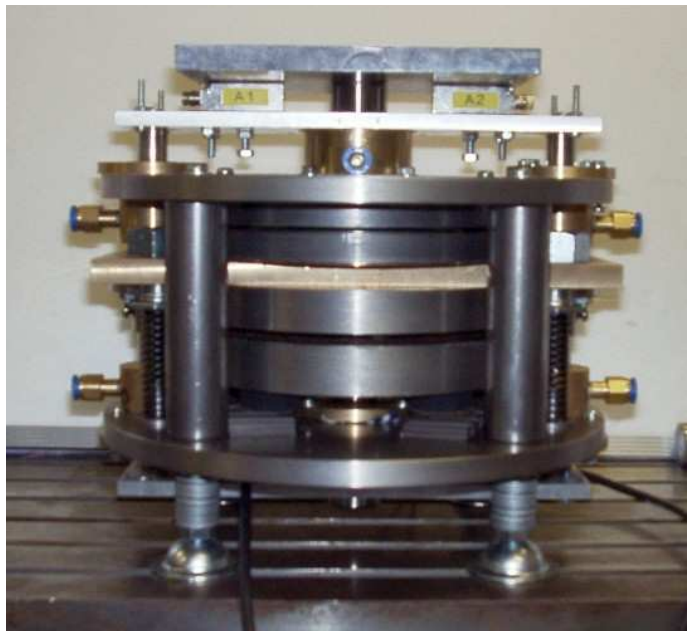

Fig. 4.3. Photo of experimental apparatus

Apparatus. Figures 4.2 and 4.3 are a schematic diagram and a photograph of a single-axis apparatus that was built for experimental study. The height, diameter, and mass of the apparatus are $200 \mathrm{~mm}, 226 \mathrm{~mm}$ and $18 \mathrm{~kg}$, respectively. The isolation table and the middle mass weigh $3.5 \mathrm{~kg}$ and $5 \mathrm{~kg}$, respectively, and are guided to move translationally in the vertical direction by linear air bearings. A ring-shape electromagnet with a 448-turn coil is fixed to the middle mass; its inner and outer diameters are 68 and $138 \mathrm{~mm}$, respectively. Ten $10 \times 10 \times 5$-mm permanent magnets made of $\mathrm{NdFeB}$ provide bias flux. These magnets, rather than the electromagnet, are built in the reaction part of the isolation table. The nominal gap between the electromagnet and the permanent magnets is about $3 \mathrm{~mm}$. The middle mass is suspended by four mechanical springs. An electromagnet for adjusting the positive stiffness 
$k_{1}$ and the damping $c_{1}$ is installed on the base, and its reaction part is built in the middle mass. The electromagnet is referred to as an auxiliary electromagnet and is used to equalize the positive stiffness and the amplitude of the negative stiffness in the following experiment. The relative displacement of the middle mass to the base and that of the isolation table to the middle mass are detected by eddy-current gap sensors.

In the experiments, we use a zero-power controller in the form of

$$
i=-\left(p_{d}+p_{v} \frac{d}{d t}\right)\left(x_{2}-x_{1}\right)+p_{i} \int i d t
$$

This is a combination of PD (proportional-derivative) control and a local integral feedback of current (Mizuno \&Takemori, 2002). Equation (4.1) states that

$$
I(s)=-\frac{s\left(p_{d}+p_{v} s\right)}{s-p_{i}}\left(X_{2}(s)-X_{1}(s)\right)=-c_{2}(s) s\left(X_{2}(s)-X_{1}(s)\right)
$$

The designed control algorithm is implemented with a digital controller. The control period is $100 \mu \mathrm{s}$. The feedback gains $p_{d}, p_{v}$, and $p_{i}$ are tuned by trial and error.

Experiments. To estimate the negative stiffness of the zero-power magnetic suspension, its force-displacement characteristics are measured when the middle mass is fixed; downward force is produced by placing weights on the isolation table. Figure 4.4 presents the measurement results. The upward displacement of the isolation table is plotted against the downward force produced by the weights. As shown in the figure, the direction of the displacement is opposite to that of the applied force so that the stiffness is negative. Figure 4.5 shows the magnitude of negative stiffness versus the applied force, which is calculated based on the measurement results shown in Fig.4.4. As the downward force increases, the gap between the electromagnet and the reaction part decreases so that the gap-displacement coefficient $k_{s}$ becomes larger. As a result, the amplitude of negative stiffness also becomes larger. However, it will be assumed to be constant in the following experiments, in which the zero-power magnetic suspension system is combined with a suspension mechanism with positive stiffness. The average value of $k_{s}$ is $14.3 \mathrm{kN} / \mathrm{m}$ in the range of force 0 to $9 \mathrm{~N}$, which is treated as a nominal value (Mizuno et al., 2006a).

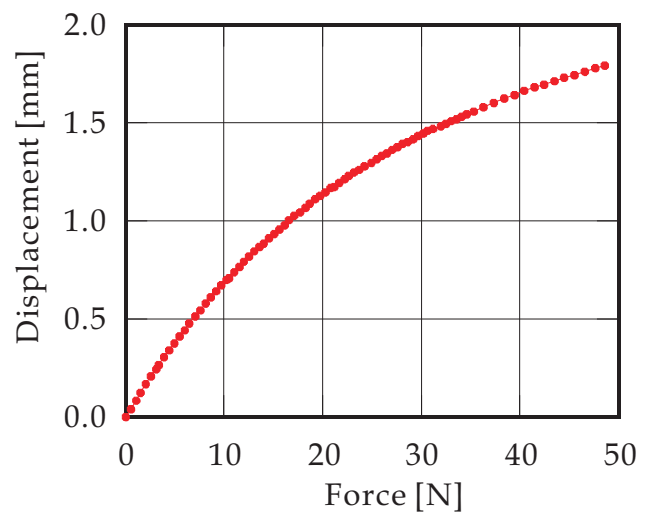

Fig. 4.4. Force-displacement characteristics of the zero-power magnetic suspension 


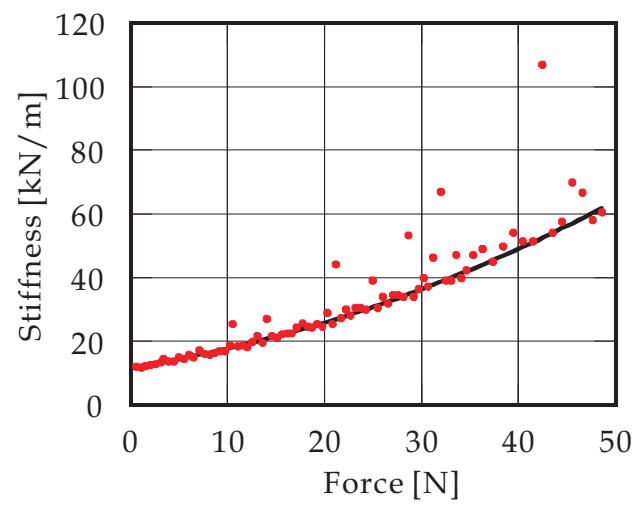

Fig. 4.5. Amplitude of the negative stiffness of the zero-power magnetic suspension system

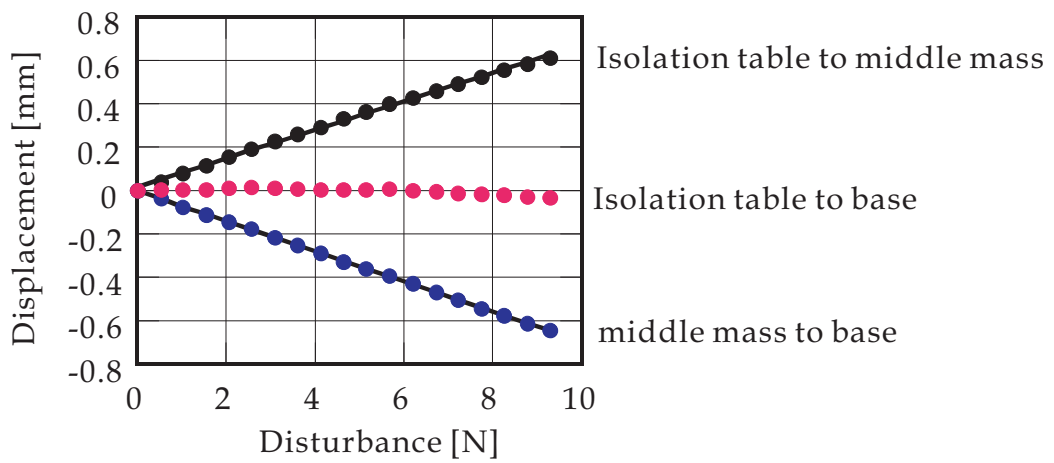

Fig. 4.6. Displacements of the isolation table and the middle mass

In the second experiment, the middle mass is released so that it is supported by the springs, and weights are again added onto the isolation table as a direct disturbance. Since the positive stiffness by the springs is $12.5 \mathrm{kN} / \mathrm{m}$, it is adjusted to equal the nominal value $14.3 \mathrm{kN} / \mathrm{m}$ by the auxiliary electromagnet. It should be noted that this type of adjustment can be achieved by changing the springs.

Figure 4.6 shows the displacement of the isolation table to the base, that of the isolation table to the middle mass, and that of the middle mass to the base. The figure shows that the position of the table is maintained at the same position while the position of the middle mass changes proportionally to the force applied to the isolation table. The estimated stiffness between the isolation table and the base is $892 \mathrm{kN} / \mathrm{m}$ in this region, which is about 63 times $k_{1}$ and $k_{s}(14.3 \mathrm{kN} / \mathrm{m})$. This result demonstrates well that combining a zeropower magnetic suspension with a normal spring can generate high stiffness against a static direct disturbance acting on the isolation table.

Since the magnitude of negative stiffness is a function of the gap between the electromagnet and the reaction part, the stiffness against the direct disturbance will decrease when the amplitude of the disturbance exceeds a certain level. Three approaches are proposed for resolving this problem. One is to apply a nonlinear compensation to the zero-power controller (Hoque et al., 2006b). Another is to use a linear actuator instead of the hybrid 


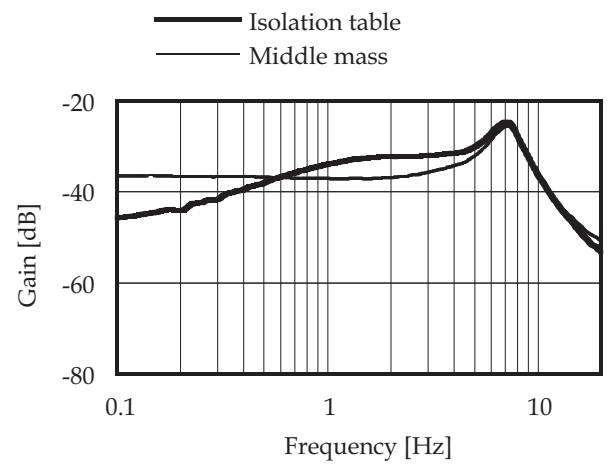

(a) Gain

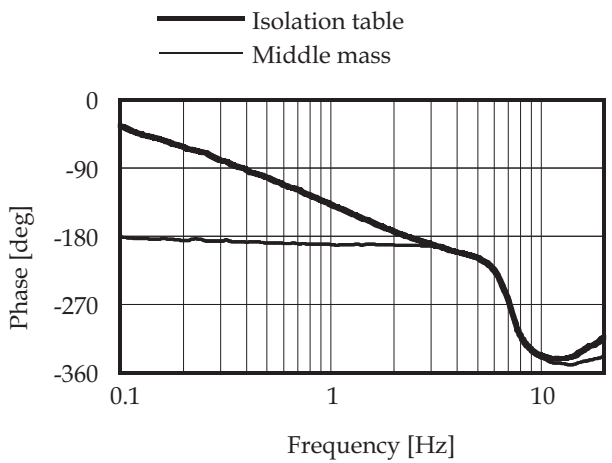

(b) Phase

Fig. 4.7. Frequency response of the vibration isolation system to direct disturbance

magnet to produce negative stiffness as treated in Section 5 (Mizuno et al., 2003a). The other is to use a nonlinear spring to produce positive stiffness (Mizuno et al., 2003b).

Figure 4.7 shows a frequency response of the system to direct disturbance. A sinusoidal disturbance was produced by an electromagnet, which was installed over the isolation table for measurement. The command signal inputted to the amplifier was treated as an input signal while the displacement of the isolation table to the base and that of the middle mass to the base were treated as output signals. As can be seen in the figure, the displacement of the isolation table is reduced at a frequency range lower than $1 \mathrm{~Hz}$. This result also supports the conclusion that the proposed system can generate high stiffness against a static direct disturbance acting on the isolation table.

The dynamic performances of the system, i.e., its responses to sinusoidal and stepwise direct disturbances, depend on the control performance. In this work, the controller was tuned by trial and error, as mentioned above. To improve more effectively the dynamic performance of the system, further intensive study on the applications of advanced-control design methods will be necessary. Since the performances of the system also depends on physical parameters such as $k_{1}, c_{1}$ and $m_{2}$, the integrated design of mechanism and control using optimization techniques offers a promising approach to optimizing performance. 


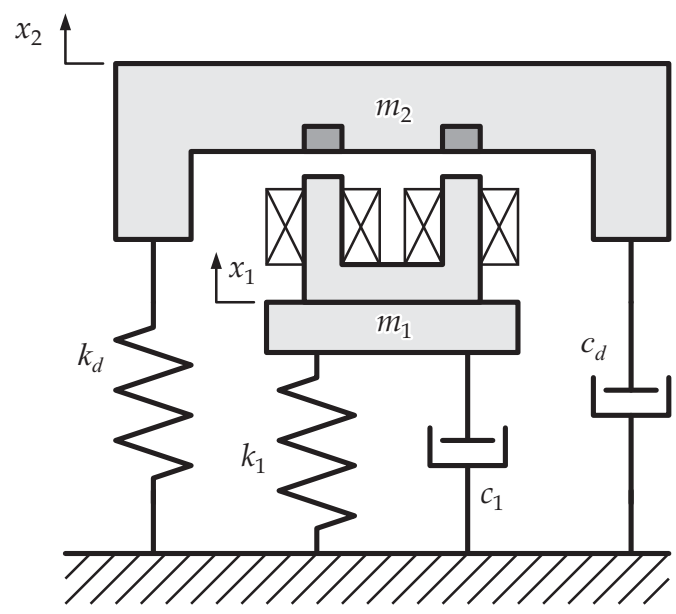

Fig. 4.8. Vibration isolation system with a weight support mechanism

\subsection{Single-axis system with a weight support mechanism}

Basic Structure. The systems using zero-power magnetic suspension have several problems. One of them is that the whole weight of the isolation table is supported by zero-power magnetic suspension; when the isolation table is large, it is necessary to use a lot of permanent magnets. Another problem is that a ferromagnetic part of the isolation table must be under the middle table, because zero-power magnetic suspension can produce only attractive force. It makes the structure of vibration isolation system rather complex. These problems can e overcome by introducing a weight support mechanism as mentioned in Section 2.2 (Mizuno et al., 2006a).

A basic structure of a modified vibration isolation system is shown in Fig.4.8. This configuration is possible when an upward force produced by the parallel spring $k_{d}$ can be made larger than gravitational force. This structure is simpler than the original one so that it will be better in manufacturing.

Apparatus. Figure 4.9 shows a schematic diagram of a single-axis apparatus fabricated for experimental study (Mizuno et al., 2006b). The isolation table is supported by four coil springs and a pair of plate springs, which operate as $k_{d}$ in Fig.4.8. The middle table is also supported by four coil springs and a pair of plate springs, which operate as $k_{1}$ in Fig.4.8. The plate springs restrict the motion of the isolation table and the middle table to one translational motion in the vertical direction. An electromagnet is on the middle table, and permanent magnets are on the isolation table. The zero-power control is realized by this hybrid magnet to produce negative stiffness. An auxiliary electromagnet for adjusting the positive stiffness and adding damping is set on the base. Figure 4.10 shows a photograph of the experimental apparatus.

Experiments. First, zero-power control was realized when the middle table was fixed. Then the middle table was released. In order to satisfy $k_{1}=k_{n}$, the springs for weight support mechanism and the auxiliary electromagnet were adjusted. The experimental results for static characteristics of the isolation table are shown in Fig.4.11. When the load is between 0 to $10[\mathrm{~N}]$, the displacement of the isolation table is quite small so that high stiffness is achieved. When the load is over $10[\mathrm{~N}]$, the isolation table moves upward because the 


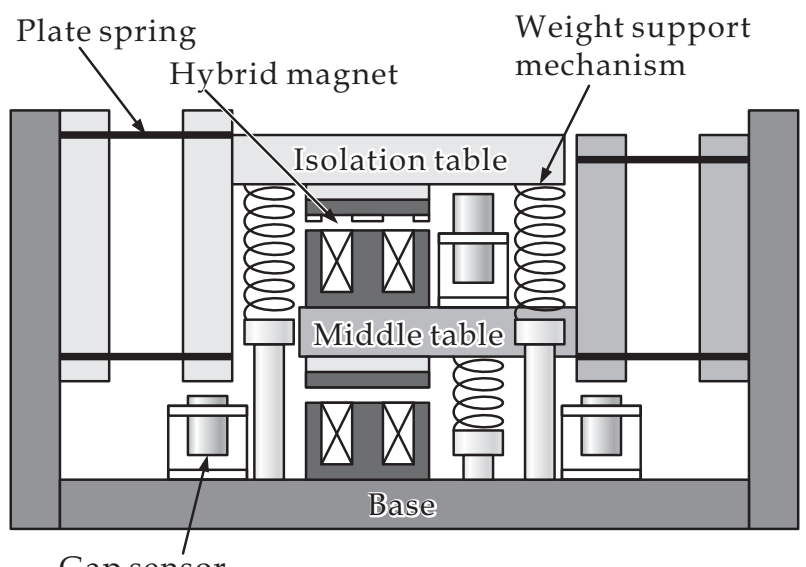

Gap sensor

Fig. 4.9. Schematic drawing of experimental apparatus with a weight support mechanism

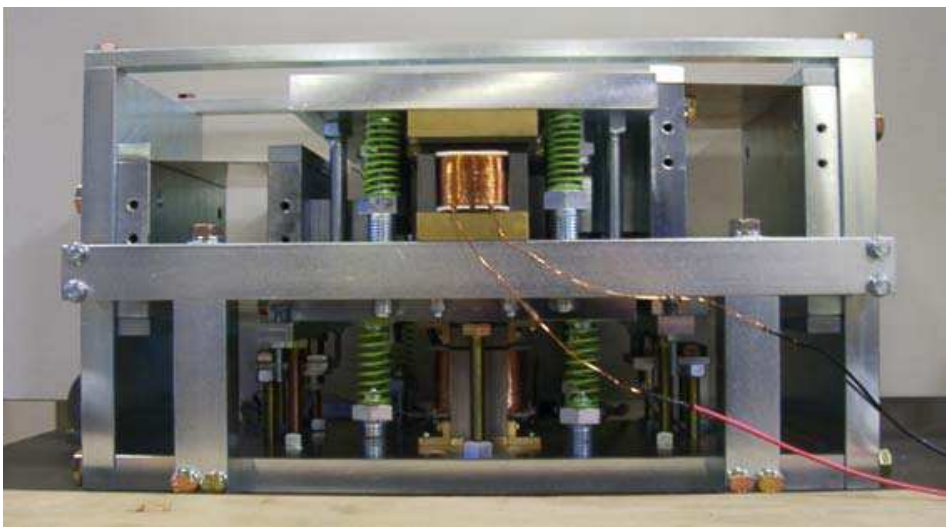

Fig. 4.10. Photo of experimental apparatus

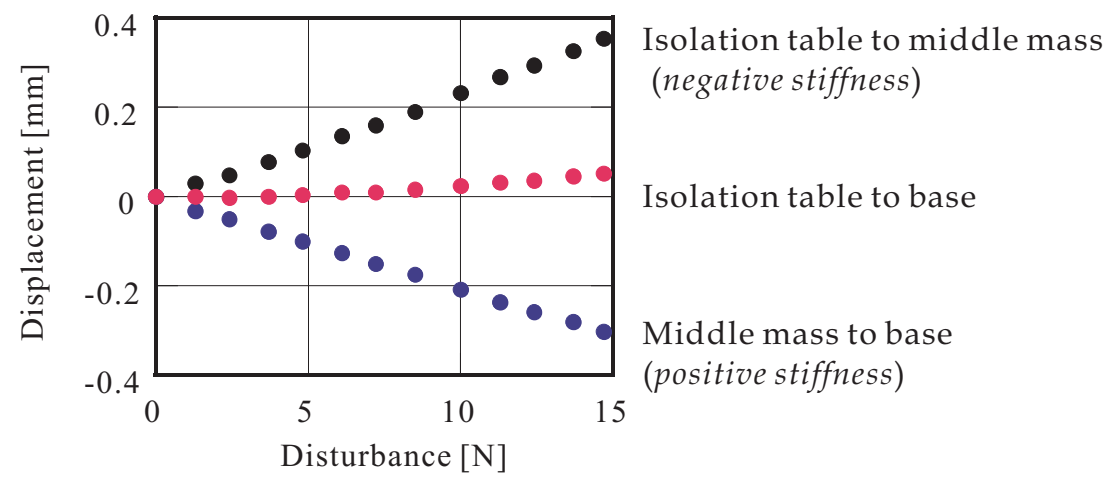

Fig. 4.11. Response to static direct disturbance 


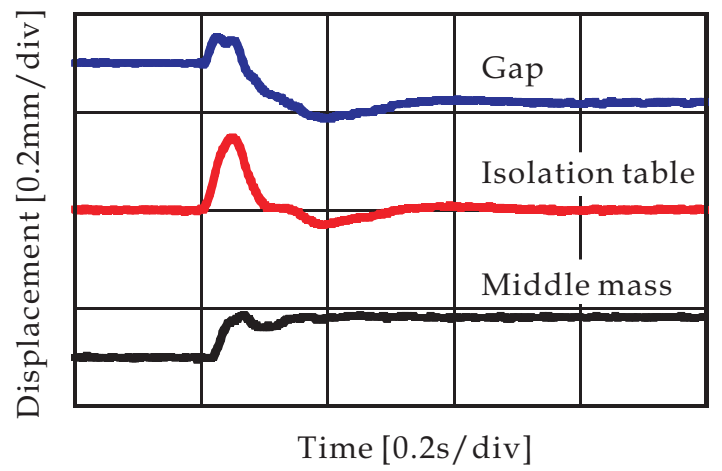

Fig. 4.12. Response to a stepwise direct disturbance

negative stiffness produced by zero-power control becomes lower. This is caused by non linear characteristics of magnets.

Figure 4.12 shows a response to a stepwise direct disturbance that was produced by the electromagnet over the isolation table. An upward force applied to the isolation table initially was quickly removed by making the coil current zero. The middle mass begins to move downward and stay at a position that is lower than the initial position. The relative displacement of the isolation table to the middle mass is negative just after the applied force is removed and then positive at steady state. The former displacement is cancelled by the latter one so that the position of the isolation table returns to its initial position at steady state.

\subsection{Six-axis system with weight support mechanism}

Apparatus. For studying multi-axis vibration control, three-axis and six-axis vibration isolation systems have been developed (Hoque et al., 2006a and 2007). The latter is treated here. Figures 4.13 and 4.14 show a photo and a schematic drawing. It consisted of a rectangular isolation table, middle table and base. The height, length, width and mass of the apparatus were $300 \mathrm{~mm}, 740 \mathrm{~mm}, 590 \mathrm{~mm}$ and $400 \mathrm{~kg}$ respectively. The isolation and middle tables weighed $88 \mathrm{~kg}$ and $158 \mathrm{~kg}$ respectively. The middle table was supported by four pair of coil springs and dampers, and the isolation table was supported by another four coil springs, as weight support springs, in addition to the zero-power control system by four sets of hybrid magnets. The sensor and hybrid magnet positions for controlling vertical and horizontal modes are shown in Fig. 4.15. The actuators ( 1 to 4$)$ were used for table levitation as well as for controlling the three-degree-of-freedom motions ( $z$, roll and pitch) of the table in the vertical direction. Each set of hybrid magnet for zero-power suspension consisted of five square-shaped permanent magnets and five 585-turn electromagnets. The permanent magnet is made of $\mathrm{NdFeB}$ materials. The stiffness of each normal spring was $12.1 \mathrm{~N} / \mathrm{mm}$ and that of weight support spring was $25.5 \mathrm{~N} / \mathrm{mm}$. There was flexibility to change the position of the weight support springs to make it compatible for designing stable zeropower controlled magnetic suspension system.

The relative displacements of the isolation table to the middle table and those of the middle table to the base were detected by eight eddy-current gap sensors. The displacements of the isolation table from base were measured by another four gap sensors. 


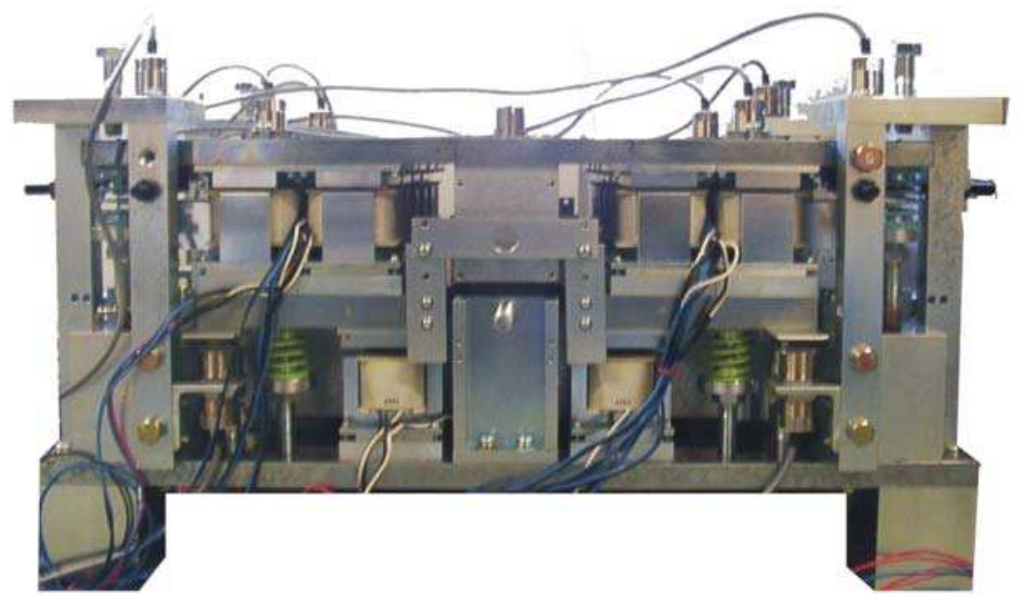

Fig. 4.13. Photo of 6-axis vibration isolation system with weight support mechanism

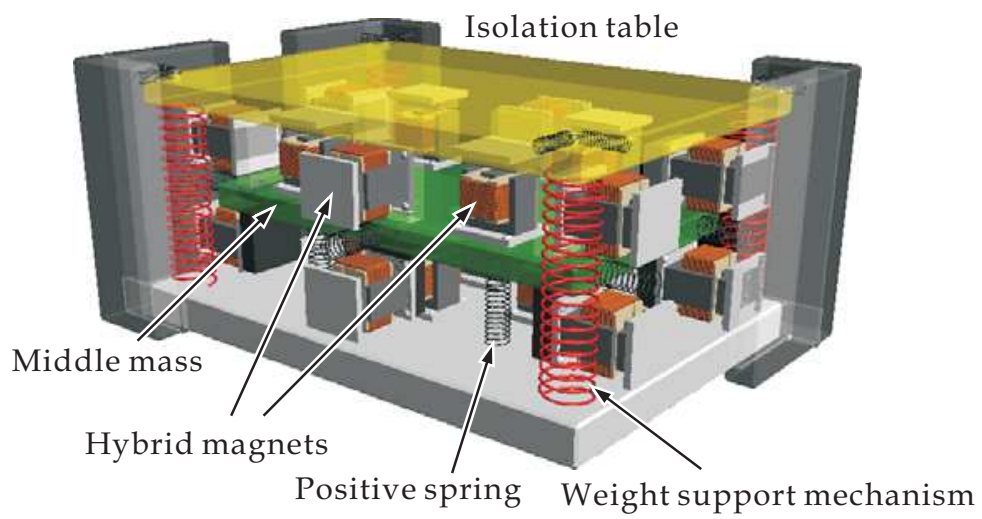

Fig. 4.14. Schematic drawing of the 6-axis vibration isolation system

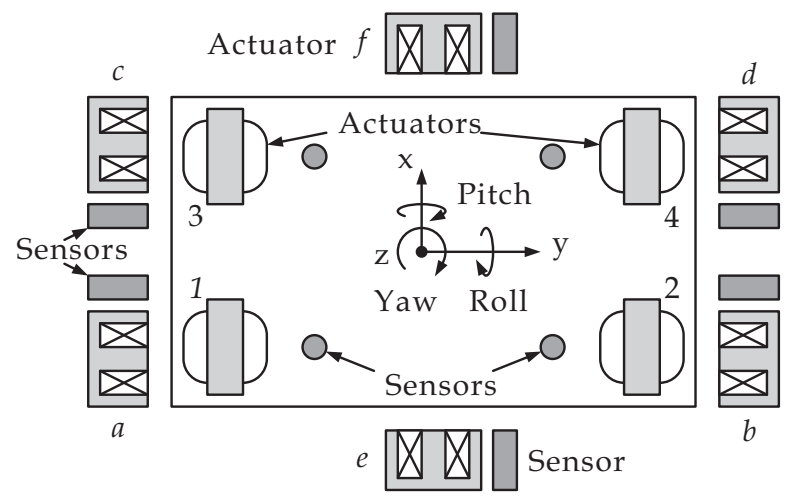

Fig. 4.15. Layout of actuators for 6-DOF motion control 


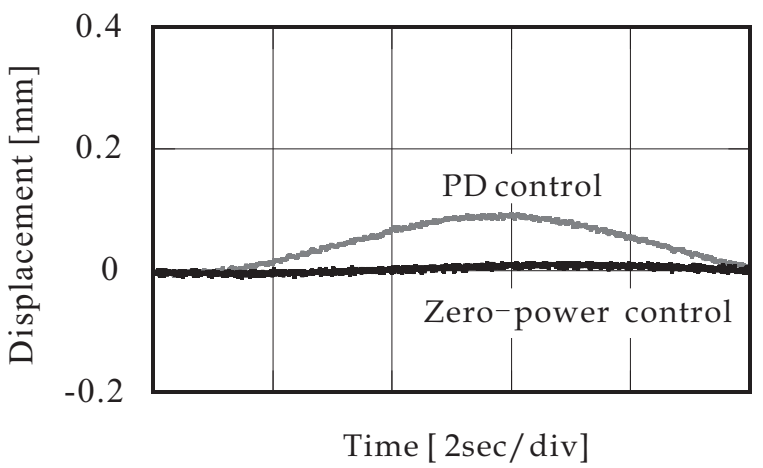

Fig. 4.16. Response to a sinusoidal direct disturbance

The isolation table was also supported by several normal springs and hybrid magnets for controlling other three-degree-of-freedom motions ( $x, y$ and yaw) in the horizontal directions. The layout of actuators ( $a$ to $f$ ) for controlling the horizontal modes is also shown in Fig.4.15. Two pairs of hybrid magnets were used in the $y$-direction and one pairs in the $x$ direction between isolation table to middle table. Similarly six pairs of normal springs and actively controlled electromagnets (two pairs in the $x$-direction and four pairs in the $y$ direction) were used between base to middle table to adjust the positive stiffness. The isolation table was also supported by four pairs of normal springs from base, as weight support spring for the horizontal directions. Hence the isolation table was also capable to control the other three modes in the horizontal directions. One pair of displacement sensors were used in the $x$ direction and two pairs in the y-direction to measure the relative displacement between isolation table to middle table for horizontal displacements. Similarly six pairs of sensors were used to measure the relative displacement between middle table to base.

Experiments. Figure 4.16 shows the response in the vertical direction to a sinusoidal direct disturbance with a frequency of $0.015 \mathrm{~Hz}$. When PD control is applied to control by the hybrid magnets, the isolation behaves as if it is suspended by conventional spring and damper. Thus, it moves due to the direct disturbance. In contrast, the table does not move when the zeropower control is applied because high stiffness is achieved according to Eq.(2.2).

\section{Vibration isolation system using pneumatic actuator}

In the zero-power magnetic suspension system, the magnitude of negative stiffness is a function of the gap between the electromagnet and the suspended object. When the mass on the isolation table changes, therefore, the negative stiffness varies from the nominal value so that the stiffness against disturbances acting on the isolation table becomes lower (Mizuno et al., 2006a). In this paper, we propose to use a linear actuator instead of an electromagnet for generating a suspension system with negative stiffness. It enables the vibration isolation system to keep high stiffness for a wider range of operation than the original system.

\subsection{Single-axis system}

A pneumatic cylinder of diaphragm type is fabricated for the realization of suspension with negative stiffness (Mizuno et al., 2005). Figure 5.1 and 5.2 show its schematic drawing and photograph. This type of cylinder is characterized by short stroke and small friction. 

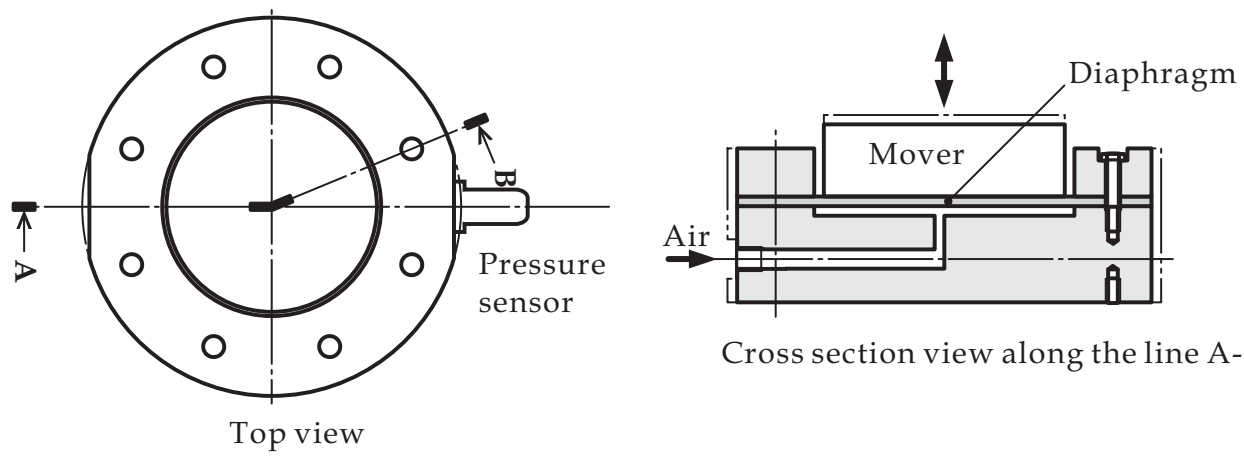

Cross section view along the line A-B

Fig. 5.1. Schematic drawing of pneumatic cylinder
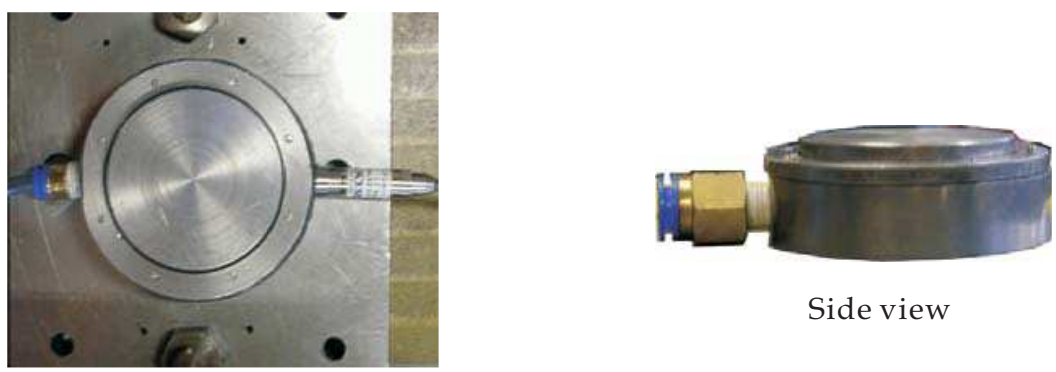

Side view

Top view

Fig. 5.2. Photo of pneumatic cylinder

The treatment of the dynamics of this cylinder is similar to that of VCM described in Section 3.2. The stiffness of the suspension system using this cylinder can be set arbitrary theoretically (Mizuno et al., 2005).

Figure 5.3 shows a schematic drawing of the developed experimental apparatus with four cylinders. Each cylinder has a diaphragm made of rubber with a thickness of $2 \mathrm{~mm}$. Its effective sectional area is $50 \mathrm{~cm}^{2}$ so that the generated force is approximately $500 \mathrm{~N}$ when the gauge pressure of supply air is $0.1 \mathrm{MPa}$. To reduce the mass of the apparatus, therefore, two cylinders are operated in a differential mode, which are referred to as a dual-cylinder.

One dual-cylinder suspends the middle mass and operates as a suspension with positive stiffness. Another dual-cylinder fixed on the middle mass suspends the isolation table and operates as a suspension with negative stiffness. These cylinders are controlled with flow control valves.

The middle mass and the isolation table are guided to be in translation by plate springs. The relative displacement of the middle mass to the base and that of the isolation table to the middle mass are detected by eddy-current gap sensors with a resolution of $1 \mathrm{~mm}$. Designed control algorithms are implemented with a DSP-based digital controller.

First, suspension with prescribed negative stiffness is realized by the pneumatic actuator was estimated. The middle mass is clamped in this experiment. The amplitude of negative stiffness is set to be
(a) $k_{n}=300[\mathrm{kN} / \mathrm{m}]$,
(b) $k_{n}=400[\mathrm{kN} / \mathrm{m}]$,
(c) $k_{n}=500[\mathrm{kN} / \mathrm{m}]$. 


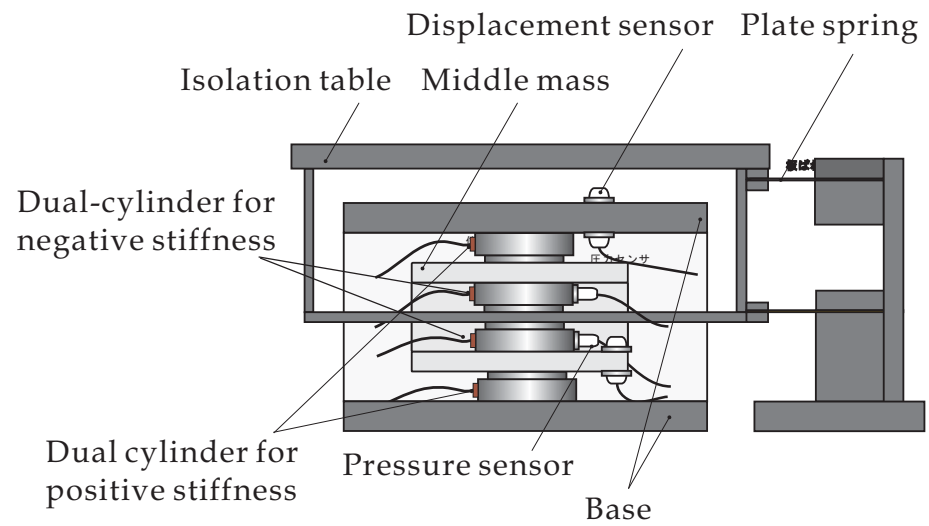

Fig. 5.3. Experimental apparatus

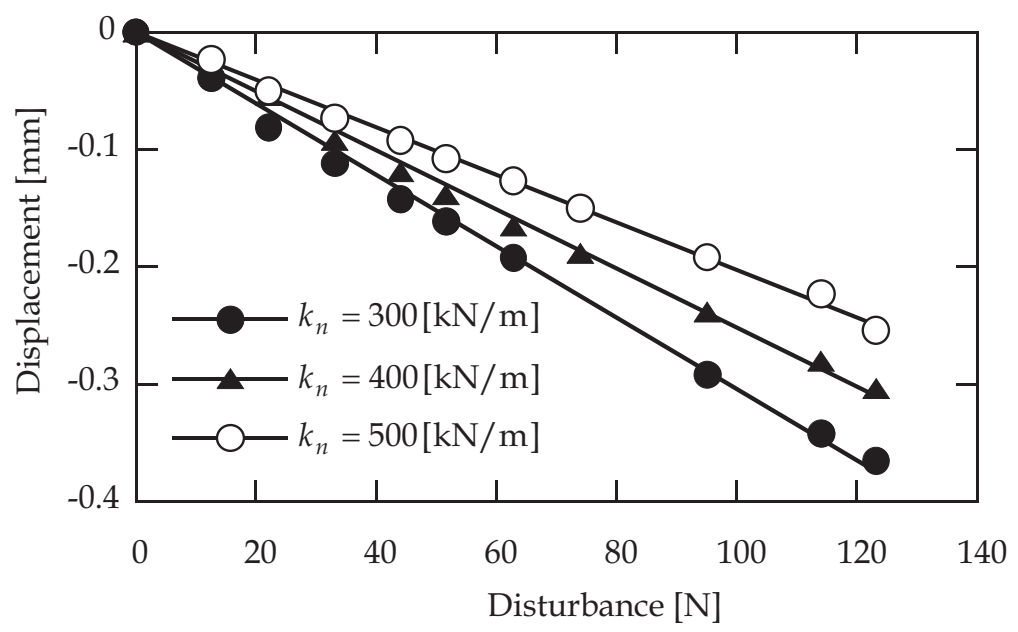

Fig. 5.4. Realization of suspension with negative stiffness

Figure 5.4 shows the measurement results. The estimated amplitude of stiffness is

(a) $k_{n}=328[\mathrm{kN} / \mathrm{m}]$,

(b) $k_{n}=398[\mathrm{kN} / \mathrm{m}]$,

(c) $k_{n}=493[\mathrm{kN} / \mathrm{m}]$.

The differences between the prescribed and experimental values are within $5 \%$. The difference is small when the amplitude of stiffness is large.

In the second experiment, the clamp of the middle mass is released. The two dual-cylinders are designed to have static stiffness of $\pm 1000[\mathrm{kN} / \mathrm{m}]$. Figure 5.5 shows the displacement of the isolation table to the base, that of the isolation table to the middle mass and that of the middle mass to the base. It is observed that the position of the isolation table is maintained at the same position while the position of the middle mass changes proportion to direct disturbance. The estimated stiffness between the isolation table and the base is $8.8 \times 10^{5}[\mathrm{kN} / \mathrm{m}]$, which is about 90 times the stiffness of each suspension. This result demonstrates that the compliance between the isolation table and the base is made very small by the proposed mechanism (Mizuno et al., 2005). 


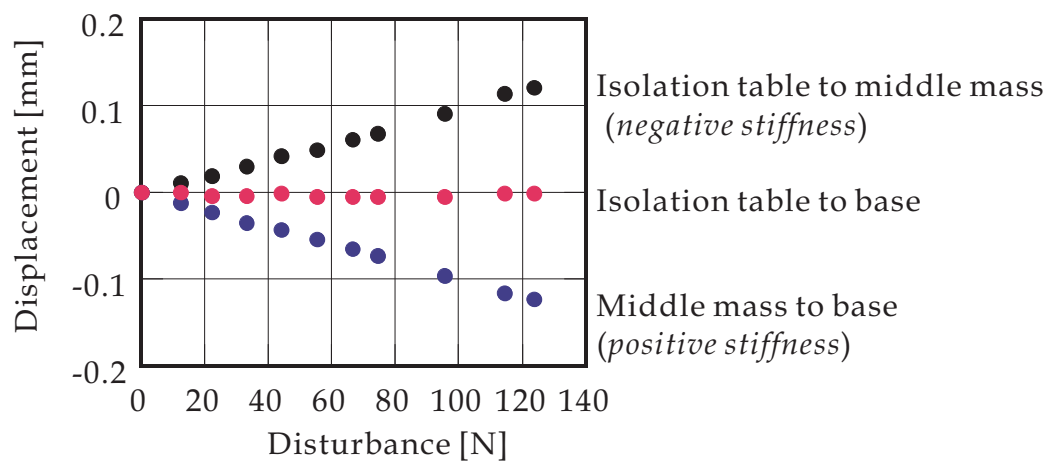

Fig. 5.5. Series connection of positive stiffness and negative stiffness

\subsection{Three-axis system using pneumatic actuators}

Apparatus. Figure 5.6 shows a photograph of a manufactured experimental apparatus with six cylinders (Mizuno et al., 2005). Its schematic diagram is presented by Fig.5.7. The diameter and height is $200 \mathrm{~mm}$ and $600 \mathrm{~mm}$, respectively. It has a circular isolation table and a circular middle table corresponding to the middle mass. The isolation and middle tables weigh $65 \mathrm{~kg}$ and $75 \mathrm{~kg}$, respectively.

The middle table is suspended by three cylinders for positive stiffness and damping. They are located at the vertices of an equilateral triangle on the base. The isolation table is suspended by three cylinders for negative stiffness, which are fixed to the middle table. Each cylinder for negative stiffness is aligned with a cylinder for positive stiffness vertically. Hence, the three-degree-of-freedom motions of the isolation table can be controlled. They are one translational motion in the vertical direction $(z)$ and two rotational motions, pitch $(\xi)$ and $\operatorname{roll}(\eta)$.

The displacements of the isolation table are detected by three eddy-current sensors, which located at the vertices of an equilateral triangle on the base. The displacement of the middle table is detected similarly. The detected places are at the middle between the actuation positions (not collocated). The displacement at the position of each cylinder, and the displacement of each motion are calculated from these detected signals.

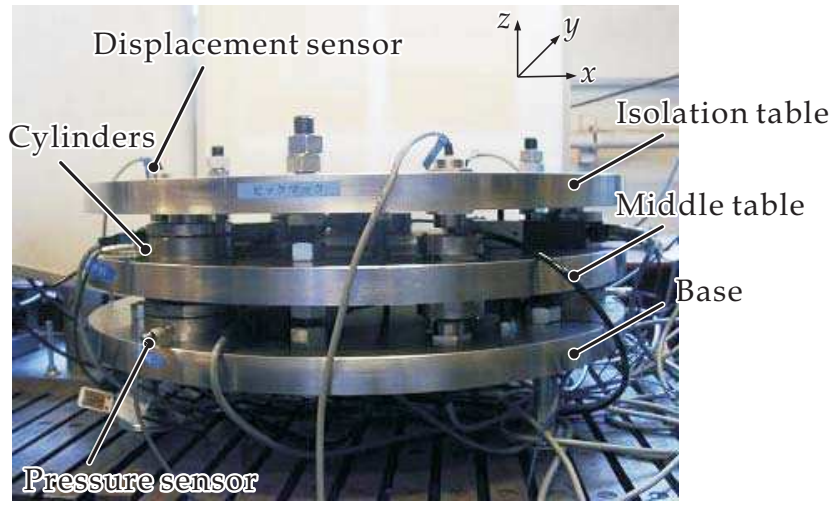

Fig. 5.6. Photo of 3-axis vibration isolation system with pneumatic actuators 
Cylinder for negative stiffness

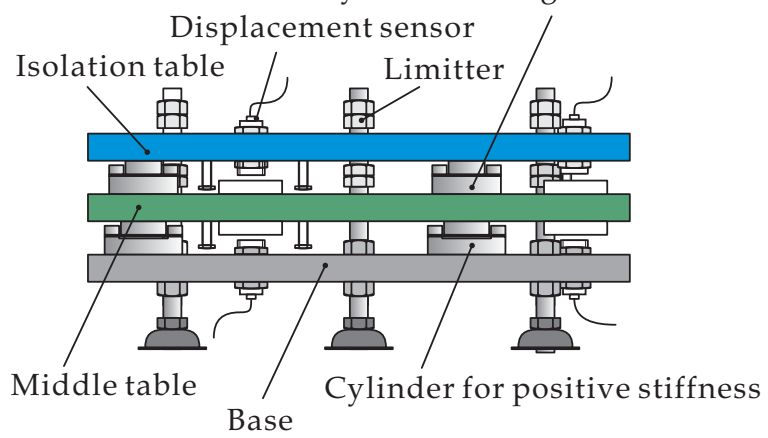

Fig. 5.7. Schematic drawing of the apparatus

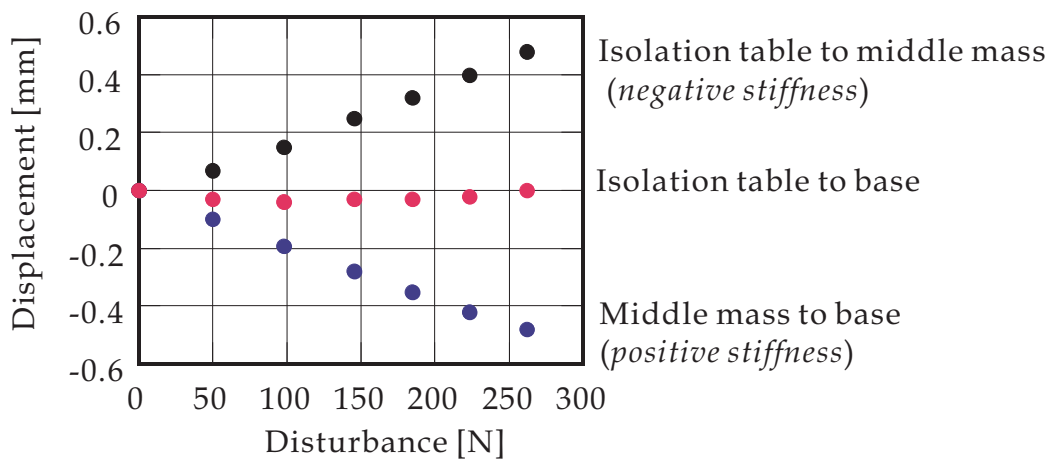

Fig. 5.8. Force-displacement characteristics of the isolation system in the vertical direction

For multi-channel control systems, there are two approaches to constructing the controller:

- local control (decentralized control)

- mode control (centralized control).

In the first controller, each actuator is controlled based on the local information, which is the displacement at the position in this case. In the second controller, a compensator is built for each mode. This work adopts the first approach.

Each controller is designed based on the pole-assignment approach as described 3.2. The order of the desired characteristic polynomial corresponding to Eq.(3.28) is six in this case (Mizuno et al., 2005). It is represented by

$$
t_{d}(s)=\prod_{n=1}^{3}\left(s^{2}+2 \varsigma_{n} \omega_{n} s+\omega_{n}{ }^{2}\right)
$$

Figure 5.8 shows the vertical displacement of the isolation table to the base. Each cylinder is controlled to have static stiffness of $\pm 250[\mathrm{kN} / \mathrm{m}]$. It is observed that the position of the isolation table is maintained at the same position while the position of the middle mass changes proportion to direct disturbance. Such performance was also achieved in the other two modes. The ratio of the total stiffness to the individual stiffness is
(a) 68 (translation),
(b) 12 (pitch),
(c) 12 (yaw) 


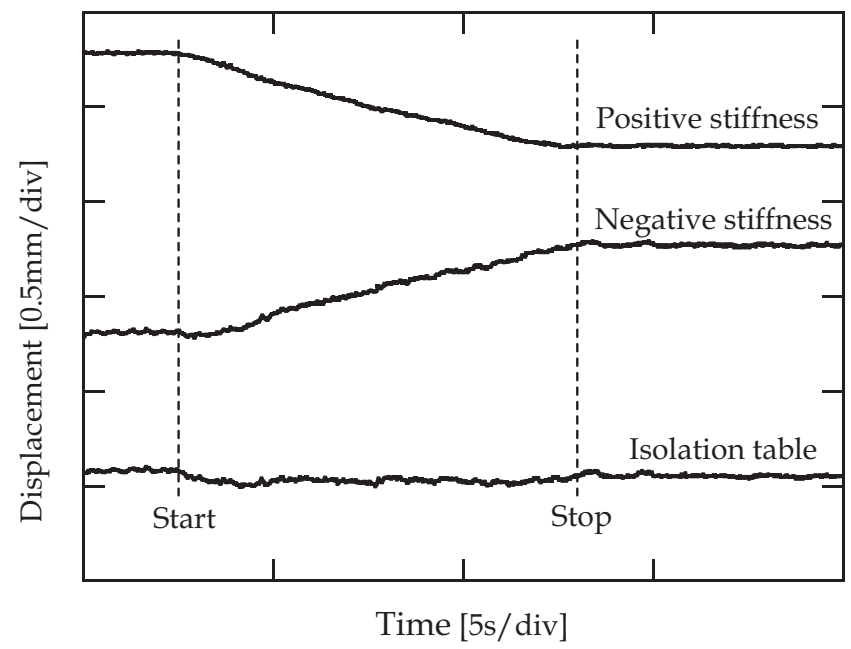

Fig. 5.9. Response to a moving mass on the table

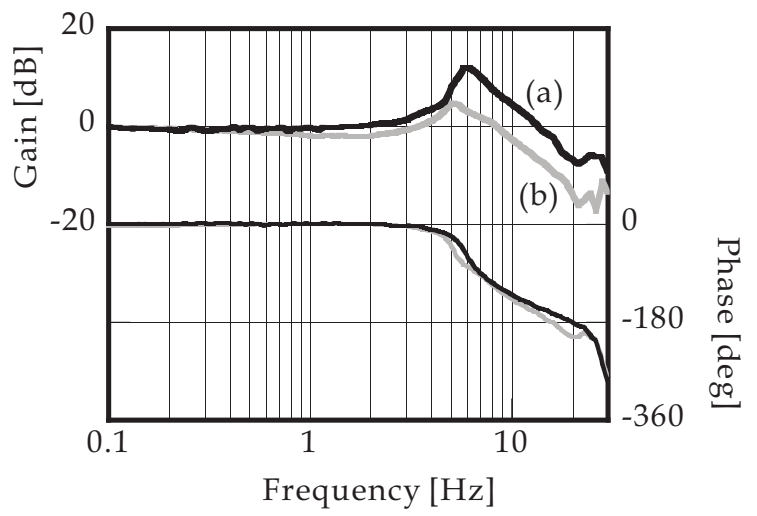

Fig. 5.10. Frequency responses to floor vibration.

This result demonstrates that the equalization of the amplitude of negative and positive stiffness enables the system to have virtually zero compliance to direct disturbance.

Figure 5.9 shows the response when a weight with a mass of $12 \mathrm{~kg}$ moves on the isolation table, which is a typical source of direct disturbance. The velocity of the movement is approximately $45 \mathrm{~mm} / \mathrm{s}$. It demonstrates that the position and attitudes of the isolation table are kept constant even with a presence of such a dynamic direct disturbance.

To study on the vibration isolation performance, frequency response to floor vibration was measured as shown by Fig.5.10 (Mizuno et al., 2005). The parameters in designing the controllers are selected as

- $\quad$ amplitude of stiffness: $500 \mathrm{kN} / \mathrm{m}$

- desired characteristic polynomial 

suspension with positive stiffness
(a) $\omega_{1}=\omega_{2}=\omega_{3}=2 \pi \times 12[\mathrm{rad} / \mathrm{s}], \zeta_{1}=\zeta_{2}=\zeta_{3}=0.7$.
(b) $\omega_{1}=\omega_{2}=\omega_{3}=2 \pi \times 5[\mathrm{rad} / \mathrm{s}], \zeta_{1}=\zeta_{2}=\zeta_{3}=1.2$.
suspension with negative stiffness
(a) $\omega_{1}=\omega_{2}=\omega_{3}=2 \pi \times 12[\mathrm{rad} / \mathrm{s}], \zeta_{1}=\zeta_{2}=\zeta_{3}=0.7$.
(b) $\omega_{1}=\omega_{2}=\omega_{3}=2 \pi \times 12[\mathrm{rad} / \mathrm{s}], \zeta_{1}=\zeta_{2}=\zeta_{3}=1.0$.

It demonstrates that the vibration isolation performance can be adjusted by the selection of the target characteristic polynomial in designing each suspension.

To improve the vibration isolation performance more, the amplitude of each stiffness should be decreased. In the fabricated system, however, the behavior of suspension became rather unstable mainly because displacement caused by direct disturbance increased when stiffness is set to be smaller. Such a problem can be solved by modifying the design of pneumatic cylinder and controller.

\section{Conclusion}

Active vibration isolation systems using negative stiffness were presented. Connecting a negative-stiffness suspension with a normal spring in series can generate infinite stiffness against disturbances acting on the isolation table. This property is maintained even if a suspension to support the weight of the isolation table is introduced in parallel with the serial combination. The principles and fundamental characteristics of the systems were described in a analytical form together with experimental apparatuses developed for experimental study and experimental results. It was experimentally confirmed that combining a negative-stiffness suspension with a normal spring in series generates high stiffness against static direct disturbance acting on an isolation table.

Vibration isolation using negative stiffness is a quite unique approach. Very high (theoretically infinite) stiffness to direct vibration is achieved with low-cost sensors while system vibration transmitted from the ground is reduced. Since negative stiffness can be achieved by any linear actuator including electromagnetic actuator (zero-power magnetic suspension), various types of system are possible. Active research and development has been and will be continued to industrial applications (Mizuno et al., 2007 \& 2008).

\section{References}

Fuller, C. R., Elliott, S. J. \& Nelson, P. A. (1996). Active Control of Vibration. Academic Press, pp.213-220.

Hoque, Md. E.,Takasaki, M., Ishino, Y. \& Mizuno, T. (2006a). Development of a Three-Axis Active Vibration Isolator Using Zero-Power Control, IEEE/ASME Transactions on Mechatronics, Vol.11, No.4, pp.462-470.

Hoque, Md. E., Mizuno, T., Takasaki, M. \& Ishino, Y. (2006b). A Nonlinear Compensator of Zero-Power Magnetic Suspension for Zero-Compliance to Direct Disturbance, Trans. the Society of Instrument and Control Engineering, Vol.42, No.9, pp.1008-1016.

Hoque, Md. E., Mizuno, T., Takasaki, M. \& Ishino, Y. (2007). Horizontal Motion Control in a Six-Axis Hybrid Vibration Isolation System using Zero-Power Control, Proc. AsiaPacific Vibration Conference 2007, G16-1-4.

Hoque, Md., E., Mizuno, T., Ishino, Y., \& Takasaki, M. (2010). A Six-Axis Hybrid Vibration Isolation System Using Active Zero-Power Control Supported by Passive Weight Support Mechanism, Journal of Sound and Vibration, Vol.329, Issue 17, pp.3417-3430. 
Miyazaki, T., Mizuno, K., Kawatani, R. \& Hamada, H. (1994). Consideration about Feedback Feedforward Hybrid Control for Active Control of Micro-Vibration Control, Proc. Second International Conference on Motion and Vibration Control, pp.29-34.

Mizuno, T. \& Takemori, Y. (2002). A Transfer-Function Approach to the Analysis and Design of Zero-Power Controllers for Magnetic Suspension System, Electrical Engineering in Japan, Vol.141, No.2, pp.67-75.

Mizuno, T., Toumiya, T. \& Takasaki, M. (2003a). Vibration Isolation System Using Negative Stiffness, JSME International Journal, Series C, Vol.46, No.3, pp.807-812.

Mizuno, T., Iwashita, S., Takasaki, M. and Ishino, Y. (2003b): Vibration Isolation System Combining Zero-Power Magnetic Suspension with a Magnetic Spring. Proc. AsiaPacific Vibration Conference 2003, pp.469-474.

Mizuno, T., Murashita, M., Takasaki, M., \& Ishino, Y. (2005). Pneumatic Active Vibration Isolation Systems Using Negative Stiffness, Trans. SICE, Vol.41, No.8, pp 676-684 (in Japanese).

Mizuno, T., Takasaki, M., Kishita, D. \& Hirakawa, K. (2006a). Vibration Isolation System Combining Zero-Power Magnetic Suspension with Springs, Control Engineering Practice, Vol.15, No.2, pp 187-196.

Mizuno, T., Kishita, D., Takasaki, M. \& Ishino, Y. (2006b). Vibration Isolation System Using Zero-Power Magnetic Suspension (2nd report: Introduction of Weight Support Mechanism), Trans. JSME, Series C, Vol.72, No.715, pp. 714-722 (in Japanese).

Mizuno, T., Unno, Y., Takasaki, M. \& Ishino, Y. (2007). Vibration Isolation Unit Combining a Air Spring with a Voice Coil Motor for Negative Stiffness, Proc. European Control Conference 2007, WeC02.2, pp.3153-3158.

Mizuno, T., Kawachi, Y., Ishino, Y. \& Takasaki, M. (2008). Vibration Isolation Unit Using Zero-Power Magnetic Suspension with a Weight Support Mechanism, Proc. 9th International Conference on Motion and Vibration Control, AV4-1298.

Morishita, M., Azukizawa, T., Kanda, S., Tamura, N. \& Yokoyama, T. (1989). A New Maglev System for Magnetically Levitated Carrier System. IEEE Trans. Vehicular Technology, Vol.38, No.4, pp.230-236.

Mohamed, Z., Martins, J.M., Tokhi, M.O., Sá da Costa, J. \&Botto, M.A. (2005). Vibration Control of a Very Flexible Manipulator System, Control Engineering Practice, Vol.13, Issue 3, pp.267-277.

Platus, D. L. (1999). Negative-Stiffness-Mechanism Vibration Isolation Systems. Proceedings of the SPIE-The International Society for Optical Engineering, Vol.3786, pp.98-105.

Rivin, E. I. (2003). Passive Vibration Isolation. ASME Press, New York, ix-xv.

Sabnis, A.V., J.B. Dendy, and F.M. Schmitt (1975). A Magnetically Suspended Large Momentum Wheel. J. Spacecraft, Vol.12, pp.420-427.

Trimboli, M.S., Wimmel, R. and Breitbach, E. (1994). A Quasi-Active Approach to Vibration Isolation Using Magnetic Springs. Proceedings of the SPIE-The International Society for Optical Engineering, Vol.2193, pp.73-83.

Yasuda, M., Osaka, T. \& Ikeda, M. (1996). Feedfoward Control of a Vibration Isolation System for Disturbance Suppression. Proc. 35th Conference on Decision and Control, pp.1229-1233.

Zhu, W.H., Tryggvason, B. \& Piedboeuf, J.C. (2006). On Active Acceleration Control of Vibration Isolation Systems, Control Engineering Practice, Vol.14, Issue 8, pp.863-873. 


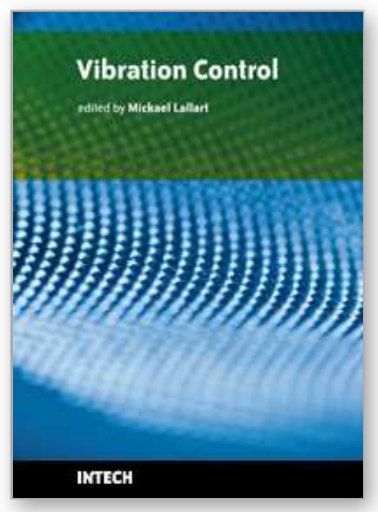

\author{
Vibration Control \\ Edited by MickaÃfÂAl Lallart
}

ISBN 978-953-307-117-6

Hard cover, 380 pages

Publisher Sciyo

Published online 18, August, 2010

Published in print edition August, 2010

Vibrations are a part of our environment and daily life. Many of them are useful and are needed for many purposes, one of the best example being the hearing system. Nevertheless, vibrations are often undesirable and have to be suppressed or reduced, as they may be harmful to structures by generating damages or compromise the comfort of users through noise generation of mechanical wave transmission to the body. the purpose of this book is to present basic and advanced methods for efficiently controlling the vibrations and limiting their effects. Open-access publishing is an extraordinary opportunity for a wide dissemination of high quality research. This book is not an exception to this, and I am proud to introduce the works performed by experts from all over the world.

\title{
How to reference
}

In order to correctly reference this scholarly work, feel free to copy and paste the following:

Takeshi Mizuno (2010). Vibration Isolation System Using Negative Stiffness, Vibration Control, MickaÃfÂ«l Lallart (Ed.), ISBN: 978-953-307-117-6, InTech, Available from: http://www.intechopen.com/books/vibrationcontrol/vibration-isolation-system-using-negative-stiffness

\section{INTECH}

open science | open minds

\section{InTech Europe}

University Campus STeP Ri Slavka Krautzeka 83/A 51000 Rijeka, Croatia

Phone: +385 (51) 770447

Fax: +385 (51) 686166 www.intechopen.com

\section{InTech China}

Unit 405, Office Block, Hotel Equatorial Shanghai No.65, Yan An Road (West), Shanghai, 200040, China 中国上海市延安西路65号上海国际贵都大饭店办公楼405单元 Phone: +86-21-62489820

Fax: $+86-21-62489821$ 
(C) 2010 The Author(s). Licensee IntechOpen. This chapter is distributed under the terms of the Creative Commons Attribution-NonCommercialShareAlike-3.0 License, which permits use, distribution and reproduction for non-commercial purposes, provided the original is properly cited and derivative works building on this content are distributed under the same license. 